Acta Crystallographica Section B

Structural Science, Crystal Engineering and Materials

ISSN 2052-5206

Chandan Dey, Tanay Kundu, Bishnu P. Biswal, Arijit Mallick* and Rahul Banerjee*

Physical and Materials Chemistry Division, CSIR-National Chemical Laboratory, Dr Homi Bhabha Road, Pune, Maharashtra 411008, India

Correspondence e-mail: a.mallick@ncl.res.in, r.banerjee@ncl.res.in

\title{
Crystalline metal-organic frameworks (MOFs): synthesis, structure and function
}

Metal-organic frameworks (MOFs) are a class of hybrid network supramolecular solid materials comprised of organized organic linkers and metal cations. They can display enormously high surface areas with tunable pore size and functionality, and can be used as hosts for a range of guest molecules. Since their discovery, MOFs have experienced widespread exploration for their applications in gas storage, drug delivery and sensing. This article covers general and modern synthetic strategies to prepare MOFs, and discusses their structural diversity and properties with respect to application perspectives.

\section{Introduction}

Crystalline metal-organic frameworks (MOFs) are one of the most important classes of porous materials, which find widespread utilization in adsorption, separation, catalysis, magnetism, sensing and drug delivery (Bellussi et al., 2013; Férey, 2008; Lalonde et al., 2013; Rosi et al., 2002). MOFs are typically constructed by connecting secondary building units (SBUs) with organic spacers to create diverse networks. The organic spacers or the metallic SBUs can be altered to control the pore environment of the MOF, which controls its interactions with adsorbates, which ultimately enables its utilization for a particular application. An enormous amount of research has been carried out on MOFs over the last two decades. Transition metals (e.g. $\mathrm{Cu}, \mathrm{Zn})$, alkaline earth elements (e.g. Sr, Ba), p-block elements (e.g. In, Ga), actinides (e.g. U, Th), even mix metals have been used for the synthesis of MOFs (Cui et al., 2012; Kong et al., 2012; Shultz et al., 2009; Stavila et al., 2012; Mallick et al., 2012; Dey et al., 2012; Kim et al., 2003). Since MOF structure depends on the choice of metals and ligands, various organic ligands of different shape and size have also been utilized to control the architecture. A noteworthy aspect in MOF chemistry is the direct structureproperty relationship, which is a hallmark of this research area.

So far, MOFs have been extensively used for adsorption and separation of gases, viz. $\mathrm{N}_{2}, \mathrm{CO}_{2}, \mathrm{H}_{2}, \mathrm{CH}_{4}$ etc., due to their porous nature (Han et al., 2009; Rowsell \& Yaghi, 2004). A huge number of nonporous MOFs are also reported in the literature, having other important applications, e.g. magnetism, luminescence and sensors, depending on the type of metals and ligands. Functionalization of MOFs with various diverse organic links has been used for selective adsorption and separation of different gases from gas mixtures (Czaja et al., 2009; Li et al., 2009). One such example is MOFs having open metal sites, which have been used to enhance $\mathrm{H}_{2}$ adsorption (Kong et al., 2012). Similarly amino-functionalized MOFs have been used for selective $\mathrm{CO}_{2}$ adsorption (Pachfule
Received 16 July 2013 Accepted 26 October 2013 
et al., 2011; An et al., 2009; Panda et al., 2011). A number of review articles have been written on the topic of MOFs, highlighting almost all aspects of this exciting research area (Ricco et al., 2013; O'Keeffe \& Yaghi, 2012). Hence, instead of focusing on one particular aspect we have attempted in this Feature Article to prepare an overview of the three most critical aspects of the field, namely synthesis, structure and properties.

\section{Synthesis}

A summary of the various approaches for MOF preparation is illustrated in Fig. 1. Most MOF syntheses are liquid-phase syntheses, where separate metal salt and ligand solutions are mixed together or solvent is added to a mixture of solid salt and ligand in a reaction vial. Selection of a solvent for these liquid-phase reactions can be based on different aspects such as reactivity, solubility, redox potential, stability constant etc. Solvent also plays an important role in determining the thermodynamics and activation energy for a particular reaction. Apart from liquid-phase synthesis, researchers have also attempted solid-phase syntheses of MOFs, because it is quicker and easier, but solid-state synthesis always faces difficulties obtaining single crystals, and thereby determining product structure, which is otherwise quite easy in solution-

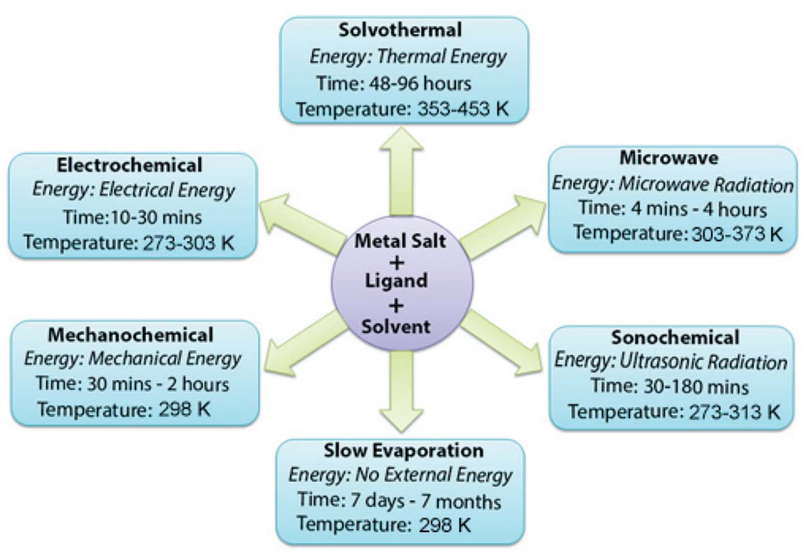

(a)

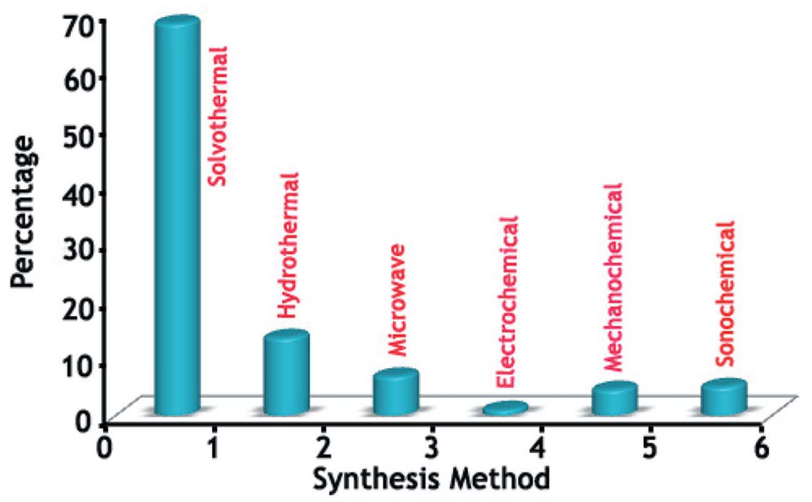

(b)

Figure 1

(a) Synthesis conditions commonly used for MOF preparation; (b) indicative summary of the percentage of MOFs synthesized using the various preparation routes. phase reactions. The slow evaporation method is a regular process of crystallization which has been applied for the last few decades to prepare MOF crystals. Although routine synthesis of MOFs involves solvothermal methods, other methods such as microwave-assisted synthesis, electrochemical synthesis, mechanochemical synthesis and sonochemical synthesis have been applied as alternatives for MOF synthesis.

\subsection{The slow evaporation method}

The slow evaporation method is a conventional method to prepare MOFs, which mostly does not need any external energy supply. Although this method is sometimes preferred because it is a room-temperature process, its major disadvantage remains that it requires more time compared with other well known conventional methods. In the slow evaporation method, a solution of the starting materials is concentrated by slow evaporation of the solvent at a fixed temperature, mostly at room temperature. Sometimes the process involves a mixture of solvents, which can increase the solubility of the reagents and can make the process faster by quicker evaporation of low-boiling solvents (Du et al., 2005; Halper et al., 2006; Ohi et al., 2004; Yoo et al., 2011).

\subsection{Solvothermal synthesis}

Solvothermal reactions are carried out in closed vessels under autogenous pressure above the boiling point of the solvent. Many starting materials can undergo quite unexpected chemical changes under solvothermal conditions, which are often accompanied by the formation of nanoscale morphologies that are not achievable by conventional methods. In most cases, high-boiling organic solvents have been used for solvothermal reactions. The most commonly used organic solvents are dimethyl formamide, diethyl formamide, acetonitrile, acetone, ethanol, methanol etc. Mixtures of solvents have also been used to avoid problems of differing solubility for the different starting materials. Solvothermal reactions can be carried out in different temperature ranges, depending on the requirement of the reaction. Generally, glass vials are used for lower temperature reactions, while reactions performed at temperatures higher than $\sim 400 \mathrm{~K}$ require Teflon-lined autoclaves (Wang \& Ying, 1999). The hydrothermal method has been used successfully for the synthesis of an enormous number of inorganic compounds and inorganic organic hybrid materials.

\subsection{Microwave-assisted synthesis}

Microwave-assisted synthesis provides a very rapid method for the synthesis of MOFs. Microwave-assisted procedures have been used extensively to produce nanosize metal oxides (Lagashetty et al., 2007). Such processes involve heating a solution with microwaves for a period of about an hour to produce nanosized crystals. The microwave-assisted synthesis has been termed 'microwave-assisted solvothermal synthesis' for the preparation of MOFs. The quality of the crystals obtained by microwave-assisted processes are generally the 
same as those produced by the regular solvothermal processes, but the synthesis is much quicker (Bux et al., 2009; Hindelang et al., 2012; Liang \& D'Alessandro, 2013; Zornoza et al., 2011: Klinowski et al., 2011).

\subsection{Electrochemical synthesis}

Although there is a possibility to prepare large MOF crystals under mild conditions by changing the $\mathrm{pH} / \mathrm{solvent}$ at room temperature, for certain applications and for the sake of fast reproducible production of large amounts of MOF samples, the development and understanding of new mild and rapid synthetic methods is ongoing. Electrochemical synthesis, being one such process, does not require metal salts and offers continuous production of MOF crystals, which is a major advantage in an industrial process. The basic principle relies on providing the metal ion by anodic dissolution into synthesis mixtures that include organic linkers and electrolytes (Martinez Joaristi et al., 2012).

\subsection{Mechanochemical synthesis}

Mechanochemical synthesis is a solvent-free synthesis method for MOFs. Mechanochemistry is the process of performing a chemical reaction by applying mechanical force. Construction of bonds through simple, economical and environmentally friendly mechanochemical routes is of considerable interest in modern synthetic chemistry. Recently, mechanochemical syntheses have been efficiently employed for the rapid synthesis of MOFs using liquid-assisted grinding (LAG), where a small amount of solvent is added into a solid reaction mixture (Beldon et al., 2010). Friščić and co-workers have shown that by varying the added solvent in a LAG process, they could obtain one-dimensional, two-dimensional and three-dimensional coordination polymers from the same reaction mixture. This strategy was applied further for the synthesis of some zeolitic imidazolate frameworks (ZIFs; Friščić et al., 2013).

\subsection{Sonochemical synthesis}

Sonochemistry is a phenomenon by which molecules undergo chemical change due to the application of intensive ultrasonic radiation $(20 \mathrm{kHz}-10 \mathrm{MHz})$. Ultrasound induces chemical or physical changes due to a cavitation process involving the formation, growth and instantaneous collapse of bubbles in a liquid, which creates local hot spots of a short lifetime with high temperature and pressure. The extreme conditions can promote chemical reactions by immediate formation of a surplus of crystallization nuclei. Sonochemical methods can generate homogeneous nucleation centres and a considerable reduction in crystallization time compared with conventional hydrothermal methods. MOF-5 synthesis using sonochemical irradiation in 1-methyl-2-pyrrolidinone (NMP) can produce $5-25 \mu \mathrm{m}$ crystals in $30 \mathrm{~min}$, which is similar to MOF-5 synthesized via solvothermal or microwave methods (Arul Dhas et al., 1998; Aslani \& Morsali, 2009; Carson et al., 2011; Dharmarathna et al., 2012; Jung et al., 2010; Kim et al., 2011; Mohanty et al., 2009; Son et al., 2008).

\section{Structure}

Lack of control over the structural integrity of traditional solid-state materials like zeolites and activated carbons is related to the fact that the starting materials do not maintain their arrangement due to poor correlation between reactants and products. By contrast, MOFs can be obtained using rigid molecular building blocks under reaction conditions that maintain their structural integrity throughout the synthesis regime. In this context, reticular synthesis can be described as the process of assembling judicious primary building blocks to form SBUs which predetermine ordered structures held together by strong coordination bonds. In a nutshell, with this strategy it is possible to control the overall coordination number of the inorganic and organic building units, and it then becomes important to identify the networks that can be expected to result from a topological point of view.

Typically, MOFs are composed of two types of primary building units or points of extension. One type is essentially organic ligands, which could be multitopic in nature. Another type is a metal atom or finite polyatomic cluster having two or more metal atoms of the same (homometallic, e.g. $\mathrm{Zn}_{4} \mathrm{O}$, $\mathrm{Zr}_{6} \mathrm{O}_{4}$ ) or different type (heterometallic, e.g. polyoxometallates). The two types of building units exhibit characteristics roles in the construction of secondary building units (SBUs). These SBUs finally self-assemble in higher dimensions to construct the MOF architecture.

The underlying topology of a structure is described by a net, assigned by a three-letter symbol such as abc (pts, soc, rht etc.). The details of nets are available as a searchable database known as the Reticular Chemistry Structure Resource (RCSR), having a collection of more than 2000 different nets (O'Keeffe et al., 2008). TOPOS, a computer program which identifies underlying nets within a structure, has a huge database of over 70000 nets (Blatov et al., 2000). A mathematical program called SYSTRE has been used to identify new nets that are not included in the RCSR database (DelgadoFriedrichs \& O'Keeffe, 2003). Nets with one type of vertex are called uninodal, whereas nets with two types of vertex are bimodal, and so on. The metal-containing building units produced during synthesis are generally polygonal or polyhedral. Although organic building units have predetermined shape and geometry, their flexibility often determines the final architecture. Hence, it is vital to identify all vertices and edges rather than just identifying the nets. In particular, all types of network structures (organic, inorganic or organic-inorganic hybrid materials) possess inherent nets, and the interest of researchers drives them for topological construction of MOF networks based on rational assembly of building units in different dimensions.

For example, a prototypical metal-organic framework, MOF-5, possess $\mathrm{ZnO}_{4}$ tetrahedra $\left[\left(\mathrm{Zn}_{4} \mathrm{O}\right) \mathrm{O}_{12}\right.$ octahedral SBU] joined by benzene dicarboxylate (BDC) ligands, resulting in a three-dimensional cubic network structure with interconnected pores of $8 \AA$ aperture and $12 \AA$ pore diameter (Fig. 2; Li et al., 1999). On the other hand, simply changing the inorganic building block from $\mathrm{Zn}_{4} \mathrm{O}$ to $\mathrm{Cr}_{3} \mathrm{O}$, keeping the 
same organic building block, results in a drastic change in structure from MOF-5 to MIL-101, a versatile type of mesoporous solid containing large cages (diameter $\sim 3 \mathrm{~nm}$ ) with both pentagonal and hexagonal windows (Fig. 2; Férey et al., 2005). Changing the organic ligand from linear BDC to triangular BTC (benzene tricarboxylic acid) and a paddlewheel SBU $\mathrm{Cu}_{2}\left(\mathrm{CO}_{2}\right)_{4}$ results in one of the most studied MOFs, viz. HKUST-1 (Chui et al., 1999). A view of the cubic unit cell of HKUST-1 reveals $\sim 1$ nm-sized channels with fourfold symmetry (Fig. 2). The nano-channels intersect to provide a three-dimensional connected network with a honeycomb arrangement of large hexagonal-shaped windows. Concisely, a suitable choice of inorganic building blocks has been explored to provide diverse SBUs along with precise control over predictable network topologies. Moreover, imparting functionality to the BDC linker opens up further possibilities to obtain a class of versatile crystalline porous
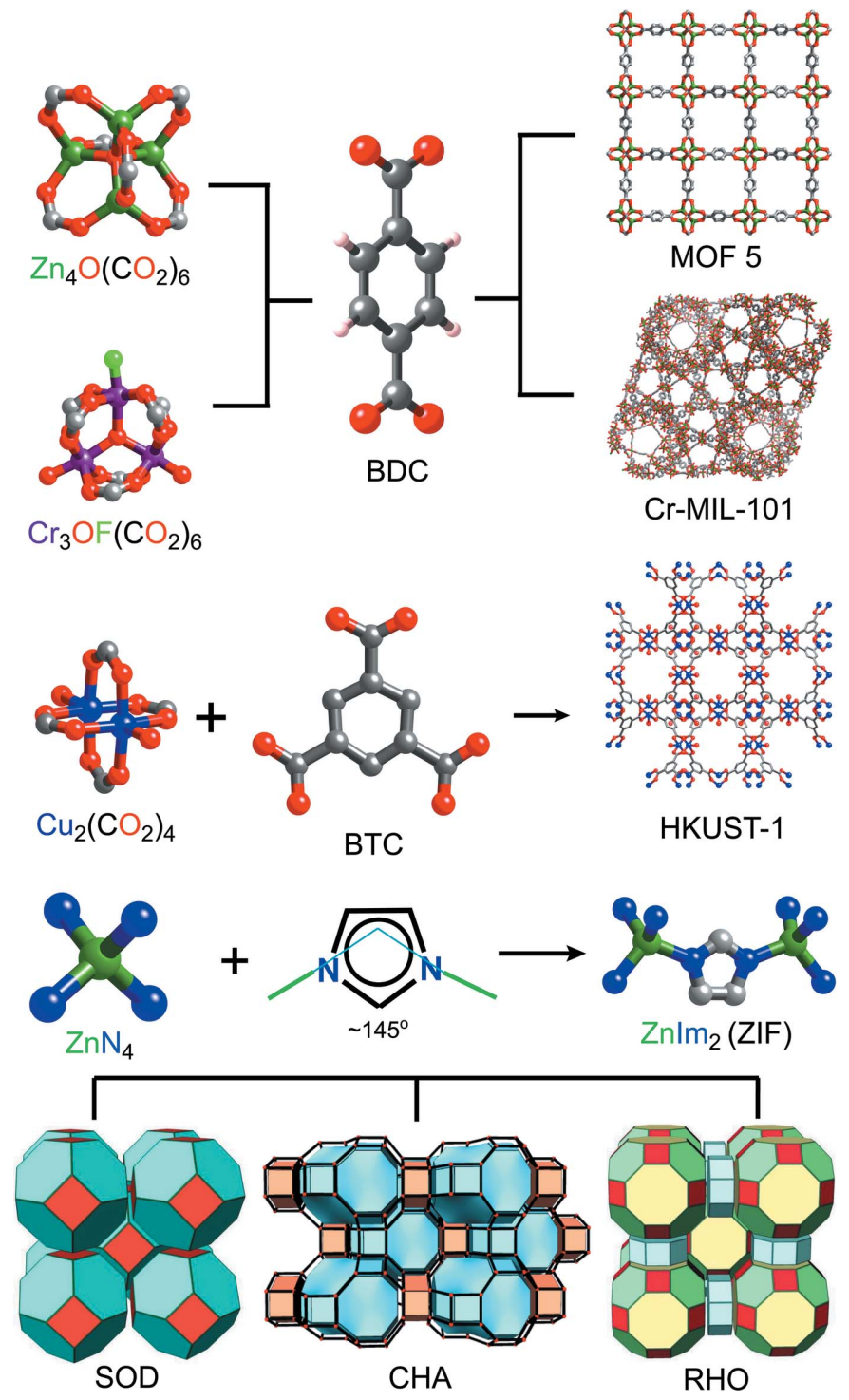

Figure 2

Examples of secondary building units (SBUs) and topologies reported in MOFs and ZIFs. materials with tailor-made properties for numerous industrially relevant applications. In a nutshell, marriage between organic and inorganic building blocks has been realised to explore a variety of MOFs with predicted topology and nets previously unrevealed in the field of extended solids.

Zeolite imidazolate frameworks (ZIFs) are three-dimensional structural analogues of zeolites, commonly based on nets of linked $\mathrm{CoN}_{4}$ or $\mathrm{ZnN}_{4}$ tetrahedra via imidazolate bridges to make an $M$-imidazolate $-M$ angle close to $145^{\circ}$ (Fig. 2) which is comparable to the $\mathrm{Si}-\mathrm{O}-\mathrm{Si}$ angle in many zeolites (Banerjee et al., 2008; Park et al., 2006). Subtle changes in reaction conditions (e.g. temperature, time, concentration, additives or structure-directing agents) can result in drastic changes in the three-dimensional structures of ZIFs, which changes the network topology and properties, while keeping both the metal and imidazolate the same. On the other hand, simple changes in linker functionality and polarity have resulted in a vast class of ZIFs with tunable porosity and properties. In addition, incorporation of multiple imidazolates in a single ZIF has been demonstrated, which opens up innumerable combinatorial possibilities of transition metal ion and functional imidazoles in the realisation of novel architectures and topologies, which is still undeveloped in zeolite chemistry.

\section{Properties}

Gases are important for energy production, and hence storage tanks are an essential requirement for effective storage of gases. Several options are available for storing gases effectively, but these mostly require high-pressure tanks and multistage compressors. Such methods are highly expensive for practical uses and there is a need for them to be substituted by simple and cheaper solutions. In an attempt to overcome these issues and to find safer storage methods, several materials, like zeolites or activated porous carbons, have been studied for gas storage. However, MOFs have outperformed most of these traditional materials in terms of gas storage and separation. Easy synthetic procedures, high surface area, wide opportunities for functionalization and tuneable pore structures make MOFs preferable compared with other porous materials. This section reviews studies of storage applications for important gases like $\mathrm{H}_{2}, \mathrm{CO}_{2}, \mathrm{CH}_{4}, \mathrm{CO}, \mathrm{NO}$, hydrocarbons etc. within MOFs, with a brief description of the factors responsible for effective storage.

\subsection{Hydrogen storage in MOFs}

Hydrogen $\left(\mathrm{H}_{2}\right)$ is considered as a possible ideal source of energy due to its large gravimetric heat of combustion $\left(120 \mathrm{MJ} \mathrm{kg}^{-1}\right)$. However, due to its low density in the gaseous state $\left(0.08 \mathrm{~kg} \mathrm{~m}^{-3}\right)$, its storage at ambient temperature and pressure is difficult. Low volumetric storage density of $\mathrm{H}_{2}$ hinders its use as a fuel and therefore effective storage materials need to be explored. The United States Department of Energy (DOE) set gravimetric and volumetric storage targets for $\mathrm{H}_{2}$ in $2010\left(6 \mathrm{wt} \%, 45 \mathrm{~g} \mathrm{~L}^{-1}\right)$ and 2015 (9 wt\%, 
$\left.81 \mathrm{~g} \mathrm{~L}^{-1}\right) . \mathrm{H}_{2}$ storage in porous MOFs is influenced by several factors such as very high surface area, functionalized polar groups, light weight, open metal centres and specific weak interactions. It has been proven that MOF materials possess the required underlying characteristics to act as high $\mathrm{H}_{2}$ uptake materials by physisorption, and they can be the best option to reach the set DOE targets in the near future. More than 300 MOFs have been tested so far for their $\mathrm{H}_{2}$ uptake capacity. One of the benchmark $\mathrm{H}_{2}$ storage materials is MOF177 , which is constructed from $\left[\mathrm{Zn}_{4} \mathrm{O}\right]$ clusters and $4,4^{\prime}, 4^{\prime \prime}$ benzene-1,3,5-triyltribenzoate (BTB) to form a $(6,3)$ net (Wong-Foy et al., 2006). Due to its high BET surface area $\left(\sim 5000 \mathrm{~m}^{2} \mathrm{~g}^{-1}\right)$ and large pore volume $\left(1.59 \mathrm{~cm}^{3} \mathrm{~g}^{-1}\right)$, it shows a gravimetric $\mathrm{H}_{2}$ uptake of $7.5 \mathrm{wt} \%$ at 70 bar and $77 \mathrm{~K}$. Another famous zinc carboxylate based MOF, MOF-5 (IRMOF-1), possesses a BET surface area of $3800 \mathrm{~m}^{2} \mathrm{~g}^{-1}$ and takes up $7.1 \mathrm{wt} \%$ of $\mathrm{H}_{2}$ at 40 bar and $77 \mathrm{~K}$. There are other MOFs which are also well known for $\mathrm{H}_{2}$ storage, such as MOF210, MIL-101, HKUST-1, NU-100, PCN-12, NOTT-102 and MOF-205 (Wang et al., 2008b; Lin et al., 2009; Farha et al., 2010; Furukawa et al., 2010). Generally, MOFs with open metal sites provide high surface area which facilitates stronger interaction between the metal ion nodes and $\mathrm{H}_{2}$ molecules. This is the principal reason behind the high $\mathrm{H}_{2}$ uptake in this promising class of materials. In addition, theoretical calculations have suggested that doping MOFs with metal ions could enhance the $\mathrm{H}_{2}$ uptake capacity.

\section{2. $\mathrm{CO}_{2}$ storage in MOFs}

The rising level of atmospheric $\mathrm{CO}_{2}$ is one of the hottest topics worldwide (Sumida et al., 2012; Sakakura et al., 2007), and its consequence is considered to provide a major threat towards living beings. The emission from coal, oil and natural gas due to rapid industrial development is mostly responsible for the rising $\mathrm{CO}_{2}$ level in the atmosphere. Earlier, zeolites and activated porous carbons were explored for $\mathrm{CO}_{2}$ adsorption, and other classes of porous materials, like MOFs, have now picked up attention as potential adsorbents. Very high internal surface area with polar functional groups decorating the pores provides opportunities for high $\mathrm{CO}_{2}$ uptake capacity in MOFs. For example, MOF-210 is the highest surface area $\left(10450 \mathrm{~m}^{2} \mathrm{~g}^{-1}\right)$ MOF known to date,

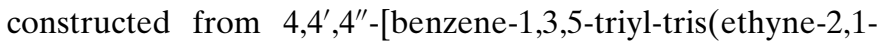
diyl)]tribenzoate $\quad\left(\mathrm{H}_{3} \mathrm{BTE}\right)$, biphenyl-4,4'-dicarboxylate ( $\mathrm{H}_{2} \mathrm{BPDC}$ ), and zinc(II)nitrate hexahydrate (Furukawa et al., 2010). Due to its ultrahigh surface area, the $\mathrm{CO}_{2}$ uptake value of MOF-210 is $2400 \mathrm{mg} \mathrm{g}^{-1}$ (74.2 wt\%, 50 bar at $298 \mathrm{~K}$ ) which exceeds that of any other porous material, such as MOF-177 or MIL-101(Cr) (60 and $56.9 \mathrm{wt} \%$, respectively; Wong-Foy et al., 2006; Férey et al., 2005). MOF-200 has a similar $\mathrm{CO}_{2}$ uptake as MOF-210 under similar experimental conditions. Other well known MOFs, such as NU-100 (69.8 wt\%, 40 bar at $298 \mathrm{~K}$ ), Mg-MOF-74 (68.9 wt\%, 36 bar at $278 \mathrm{~K}$ ), MOF-5 (58 wt \%, 10 bar at $273 \mathrm{~K}$ ), and HKUST-1 (19.8 wt\%, 1 bar at $298 \mathrm{~K}$ ), also show considerably higher $\mathrm{CO}_{2}$ uptake compared with other solid materials.
Also, it has been proven experimentally and by calculations that the presence of polar groups such as $-\mathrm{NH}_{2}$ or free $\mathrm{N}$ containing organic heterocyclic residues on the pores is helpful for high $\mathrm{CO}_{2}$ uptake compared with unfunctionalized analogues. One of the best examples, BioMOF-11, demonstrates the effects of an $\mathrm{N}$ heterocycle, and its $\mathrm{CO}_{2}$ uptake of $15.2 \mathrm{wt} \%$ (at 1 bar and $298 \mathrm{~K}$ ) exceeds any other MOF in the same category (An et al., 2009). Another of this category is ZTF-1 (Fig. 3), which shows high $\mathrm{CO}_{2}$ uptake (14.4 wt\%, 1 bar at $298 \mathrm{~K}$; Panda et al., 2011) due to the presence of free $-\mathrm{NH}_{2}$ as well as uncoordinated $\mathrm{N}$ on a tetrazole molecule within the framework. Recently, the location of $\mathrm{CO}_{2}$ molecules within a MOF structure has been identified crystallographically, which helps to understand further the structural relationship between the host and guest molecules (Vaidhyanathan et al., 2010). This will probably motivate new strategies to design functionalized MOFs for higher $\mathrm{CO}_{2}$ uptake.

\section{3. $\mathrm{CH}_{4}$ storage in MOFs}

Methane is another potential fuel, as natural gas contains about $95 \%$ of methane. Methane has a comparable gravimetric heat of combustion $\left(50.0 \mathrm{MJ} \mathrm{kg}^{-1}\right)$ to gasoline (44.5 MJ kg-1). For methane, MOFs have already achieved the DOE target of $180 \mathrm{v} / \mathrm{v}$ at ambient temperature and pressure ( $<35$ bar), but improving further the methane storage capacity is still an active area of interest (Konstas et al., 2012). Noro et al. (2000) reported the first methane sorption study in MOFs. In 2007, Zhou and co-workers showed methane uptake of $16 \mathrm{wt} \%$ (35 bar) in [PCN-14 $\mathrm{Cu}_{2}$ (adip)] MOF, with BET surface area $1753 \mathrm{~m}^{2} \mathrm{~g}^{-1}$ (Perry et al., 2007; Wang et al., 2008a). The $\mathrm{CH}_{4}$ adsorption capacity of MOF-177 is $22 \mathrm{wt} \%$ at $298 \mathrm{~K}$ and 100 bar, which is the largest adsorption uptake of $\mathrm{CH}_{4}$ among all dry solid materials (Wong-Foy et al., 2006). Other MOFs such as HKUST-1 (15.7 wt \% at $150 \mathrm{bar}$ ), MIL-101 (14.2 wt \% at $125 \mathrm{bar}$ ), IRMOF-1 [228 $\mathrm{cm}^{3}(\mathrm{STP}) \mathrm{g}^{-1}$ at $298 \mathrm{~K}$

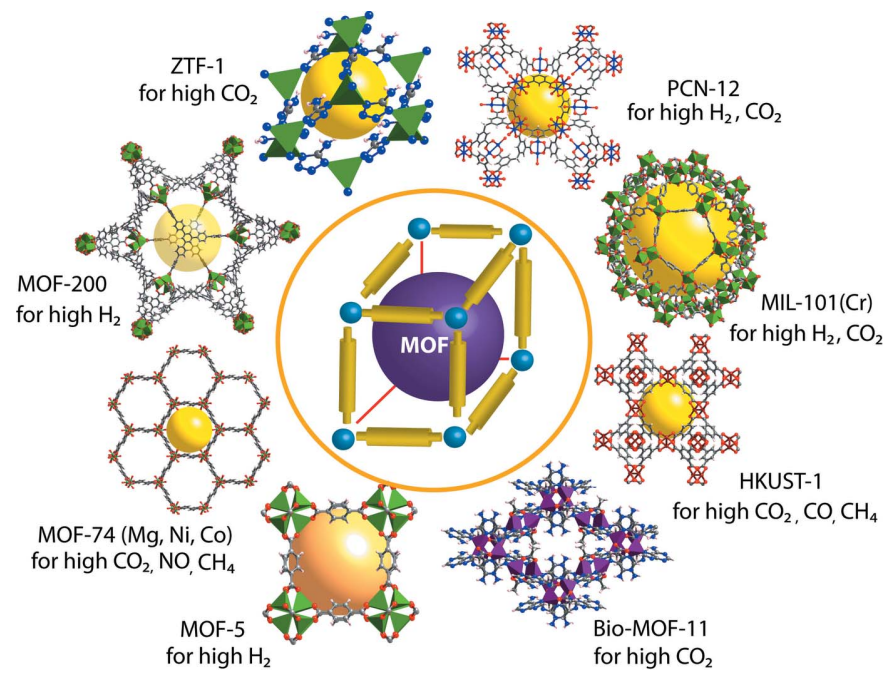

Figure 3

Schematic representation of important reported MOFs which are known for high gas storage properties. 
and $\sim 36$ bar] also show considerably high methane uptake capacity (Fig. 3). In the case of Ni-MOF-74 $\left[190 \mathrm{~cm}^{3}\right.$ (STP) $\mathrm{g}^{-1}$ ( $298 \mathrm{~K}, 35$ bar)], open metal sites are the dominating factor responsible for the high methane capacity (Wu et al., 2009). Other important hydrocarbons like benzene, toluene, xylene and linear hydrocarbons have also been effectively separated from liquid mixtures by trapping inside MOFs.

\section{4. $\mathrm{CO}$ and NO storage in MOFs}

Separation of hazardous gases like CO and NO from gas mixtures is very important, and MOFs with pores compatible with the kinetic diameter of these gases could be useful for this purpose. So far, the capture of CO in MOFs has not been achieved experimentally; it is believed that the interaction between the $\mathrm{CO}$ dipole and the open metal sites of MOFs are the dominating factor for the sorption performance. In order to achieve better selectivity, some chemical modification needs to be adopted into these porous materials. On the other hand, MOFs have been used for ultrahigh selectivity of NO gas over other gases, for example Cu-SIP-3 and Zn(TCNQTCNQ)(bipy) (Shimomura et al., 2010). Usually these two MOFs are nonporous in nature and they do not absorb gases like $\mathrm{Ar}, \mathrm{N}_{2}, \mathrm{CO}_{2}$ etc., but above gate-opening pressure (> 275 mbar) they take up NO gas $(\sim 9$ NO molecules per formula unit at $1 \mathrm{bar}$ ). On reduction of the pressure, the desorption path is not like adsorption. This is due to strong coordination to coordinatively unsaturated metal sites (CUMs) in the case of Cu-SIP-3, while for [ $\mathrm{Zn}(\mathrm{TCNQ}-$ TCNQ)(bipy)], charge transfer plays a crucial role for high NO capture (Allan et al., 2010). Ni- and Co-MOF-74 (Fig. 3) also show very high NO uptake $(\sim 7.0 \mathrm{mmol} \mathrm{NO}$ per $\mathrm{g}$ of activated material) at room temperature (McKinlay et al., 2008).

\subsection{MOFs as magnetic materials}

Magnetism in solids is of considerable interest due to its widespread applications in electromagnetism, devices and sensing. Recently, researchers have introduced magnetism within MOFs through the use of paramagnetic $3 d$ transition metal nodes along with suitable organic linkers, subsequently named as MMOFs (magnetic metal-organic frameworks). The MOFs based on first-row transition metals ( $\mathrm{V}, \mathrm{Cr}, \mathrm{Mn}, \mathrm{Fe}, \mathrm{Co}$, $\mathrm{Ni}$ and $\mathrm{Cu}$ ) have contributed significantly to developing porous molecular magnets (Cheetham \& Rao, 2007; Cheetham et al., 2006; Coronado \& Mínguez Espallargas, 2013; Kurmoo, 2009; Okawa et al., 2009; Rao et al., 2004). The porous nature of MOFs combined with magnetic properties could find interesting applications for air separation. Another important factor responsible for magnetism in MOFs is the framework structure, which may involve layered geometry with a shorter conjugated distance between the metal clusters. Organic linkers have also been used for the synthesis of MMOFs, where radicals present in the organic linker are responsible for the magnetic properties. Also metal-radical combined approaches have been used to synthesize a variety of magnetic metal-organic materials (Maspoch et al., 2003;
Roques, Maspoch, Luis et al., 2008; Roques, Maspoch, Imaz et al., 2008).

\subsection{MOFs as sensors}

The use of MOFs as luminescent materials has become an important area of research due to their potential application in small-molecule sensors (Lu et al., 2011; Sun et al., 2013), pH sensors (Harbuzaru et al., 2009), light concentrators for photovoltaic devices, antennae in photo-sensitive bioinorganic compounds and high-technology optics. MOF materials are advantageous because of their hybrid nature, which includes inorganic metal ions, organic linkers and also guest molecules. MOFs can be considered as excellent solid-state luminescent materials since they have structural predictability and well defined environments for the chromophores in crystalline form. Lanthanide metal ions are widely used for the synthesis of luminescent MOFs, due to their electronic transitions from $d$ to $f$ shells, with accompanying photon emission. Eu and $\mathrm{Tb}$ are most attractive lumophores because of their narrow emission (Reddy \& Sivakumar, 2013; Cui et al., 2012). The lanthanide metal ions are coordinated by strongly absorbing ligands, which enhances the luminescent properties of the MOFs. Other lanthanides like Dy, Sm, Nd, Gd, Er and $\mathrm{Yb}$ are also used as luminescent metal ions. Organic linkers having significant conjugation through extended $\pi$-systems are responsible for strong absorption, emission and electronic transition. In the case of organic linkers, $\pi-\pi^{*}$ and $n-\pi^{*}$ electronic transitions are commonly observed. The luminescent properties of transition-metal MOFs only come from the linkers. Different types of effect have been reported, including metal-to-ligand charge transfer (MLCT), ligand-to-metal charge transfer (LMCT), ligand-to-ligand charge transfer (LLCT) and ligand centre luminescence. Naphthalene, anthracene, pyrene, perylene and stilbene types of ligands are most commonly used for luminescent MOF synthesis (Rocha et al., 2011; Zacher et al., 2009; Zhan et al., 2013).

\section{Conclusion}

Already great strides have been made with the synthesis of MOFs and the understanding of these porous classes of material in diverse applications. The synthesis of MOFs has enhanced the scope of crystalline porous compounds with desired properties for applications in sorption, separation, magnetism, sensing, catalysis etc. Different synthesis methods have been utilized to prepare MOFs at faster rates as well as in bulk quantities, and the judicious choice of SBUs and ligands makes it possible to design topologically new compounds. Since it is possible to tune pore size and functionality inside the cavities of MOFs, these unique aspects should enable porous MOFs as useful materials for virtually all aspects of storage, separation and catalysis. Since magnetic interaction in porous MOFs depends on metal-to-metal distance and spacers between them, therefore it is also possible to tune the magnetic properties of MOFs by varying ligand length and included solvent molecules. Functionalized MOFs with open 
metal sites could enhance $\mathrm{H}_{2}$ and $\mathrm{CO}_{2}$ uptake to reach the DOE targets for the benefit of mankind. Thus, the opportunity to utilize MOF architectures is limited only by imagination and our ability to prepare and characterize adequately well designed structures.

CD, TK and AM acknowledge CSIR, New Delhi, India, for a SRF, and BPB acknowledges UGC, New Delhi, India, for a JRF. RB acknowledges CSIR's Five Year Plan (CSC0122) for funding. Financial assistance from BRNS (2011/37C/44/ BRNS) is also acknowledged.

\section{References}

Allan, P. K., Xiao, B., Teat, S. J., Knight, J. W. \& Morris, R. E. (2010). J. Am. Chem. Soc. 132, 3605-3611.

An, J., Geib, S. J. \& Rosi, N. L. (2009). J. Am. Chem. Soc. 132, 38-39. Arul Dhas, N., Raj, C. P. \& Gedanken, A. (1998). Chem. Mater. 10, 3278-3281.

Aslani, A. \& Morsali, A. (2009). Inorg. Chim. Acta, 362, 50125016.

Banerjee, R., Phan, A., Wang, B., Knobler, C., Furukawa, H., O'Keeffe, M. \& Yaghi, O. M. (2008). Science, 319, 939-943.

Beldon, P. J., Fábián, L., Stein, R. S., Thirumurugan, A., Cheetham, A. K. \& Friščić, T. (2010). Angew. Chem. Int. Ed. 49, 9640-9643.

Bellussi, G., Carati, A., Rizzo, C. \& Millini, R. (2013). Catal. Sci. Technol. 3, 833.

Blatov, V. A., Shevchenko, A. P. \& Serezhkin, V. N. (2000). J. Appl. Cryst. 33, 1193.

Bux, H., Liang, F., Li, Y., Cravillon, J., Wiebcke, M. \& Caro, J. (2009). J. Am. Chem. Soc. 131, 16000-16001.

Carson, C. G., Brown, A. J., Sholl, D. S. \& Nair, S. (2011). Cryst. Growth Des. 11, 4505-4510.

Cheetham, A. K. \& Rao, C. N. (2007). Science, 318, 58-59.

Cheetham, A. K., Rao, C. N. R. \& Feller, R. K. (2006). Chem. Commun. pp. 4780-4795.

Chui, S. S., Lo, S. M., Charmant, J. P., Orpen, A. G. \& Williams, I. D. (1999). Science, 283, 1148-1150.

Coronado, E. \& Mínguez Espallargas, G. (2013). Chem. Soc. Rev. 42 , $1525-1539$.

Cui, Y., Xu, H., Yue, Y., Guo, Z., Yu, J., Chen, Z., Gao, J., Yang, Y., Qian, G. \& Chen, B. (2012). J. Am. Chem. Soc. 134, 3979-3982.

Czaja, A. U., Trukhan, N. \& Müller, U. (2009). Chem. Soc. Rev. 38, 1284-1293.

Delgado-Friedrichs, O. \& O'Keeffe, M. (2003). Acta Cryst. A59, 351360.

Dey, C., Kundu, T. \& Banerjee, R. (2012). Chem. Commun. 48, 266268.

Dharmarathna, S., King'ondu, C. K., Pedrick, W., Pahalagedara, L. \& Suib, S. L. (2012). Chem. Mater. 24, 705-712.

Du, M., Li, C.-P. \& Zhao, X.-J. (2005). Cryst. Growth Des. 6, 335341.

Farha, O. K., Yazaydin, A. O., Eryazici, I., Malliakas, C. D., Hauser, B. G., Kanatzidis, M. G., Nguyen, S. T., Snurr, R. Q. \& Hupp, J. T. (2010). Nat. Chem. 2, 944-948.

Férey, G. (2008). Chem. Soc. Rev. 37, 191-214.

Férey, G., Mellot-Draznieks, C., Serre, C., Millange, F., Dutour, J., Surblé, S. \& Margiolaki, I. (2005). Science, 309, 2040-2042.

Friščić, T., Halasz, I., Beldon, P. J., Belenguer, A. M., Adams, F., Kimber, S. A., Honkimäki, V. \& Dinnebier, R. E. (2013). Nat. Chem. 5, 66-73.

Furukawa, H., Ko, N., Go, Y. B., Aratani, N., Choi, S. B., Choi, E., Yazaydin, A. O., Snurr, R. Q., O'Keeffe, M., Kim, J. \& Yaghi, O. M. (2010). Science, 329, 424-428.

Halper, S. R., Do, L., Stork, J. R. \& Cohen, S. M. (2006). J. Am. Chem. Soc. 128, 15255-15268.
Han, S. S., Mendoza-Cortés, J. L. \& Goddard, W. A. (2009). Chem. Soc. Rev. 38, 1460-1476.

Harbuzaru, B. V., Corma, A., Rey, F., Jordá, J. L., Ananias, D., Carlos, L. D. \& Rocha, J. (2009). Angew. Chem. Int. Ed. 48, 6476-6479.

Hindelang, K., Vagin, S. I., Anger, C. \& Rieger, B. (2012). Chem. Commun. 48, 2888-2890.

Jung, D. W., Yang, D. A., Kim, J., Kim, J. \& Ahn, W. S. (2010). Dalton Trans. 39, 2883-2887.

Kim, J.-Y., Norquist, A. J. \& O'Hare, D. (2003). J. Am. Chem. Soc. 125, 12688-12689.

Kim, J., Yang, S., Choi, S. B., Sim, J., Kim, J. \& Ahn, W. (2011). J. Mater. Chem. 21, 3070-3076.

Klinowski, J., Paz, F. A. A., Silva, P. \& Rocha, J. (2011). Dalton Trans. 40, 321-330.

Kong, X., Scott, E., Ding, W., Mason, J. A., Long, J. R. \& Reimer, J. A. (2012). J. Am. Chem. Soc. 134, 14341-14344.

Konstas, K., Osl, T., Yang, Y., Michael, B., Burke, N., Hill, A. J. \& Hill, M. R. (2012). J. Mater. Chem. 22, 16698-16708.

Kurmoo, M. (2009). Chem. Soc. Rev. 38, 1353-1379.

Lagashetty, A., Havanoor, V., Basavaraja, S., Balaji, S. D. \& Venkataraman, A. (2007). Sci. Technol. Adv. Mater. 8, 484-493.

Lalonde, M., Bury, W., Karagiaridi, O., Brown, Z., Hupp, J. T. \& Farha, O. K. (2013). J. Mater. Chem. A, 1, 5453-5468.

Li, H., Eddaoudi, M., O'Keeffe, M. \& Yaghi, O. M. (1999). Nature, 402, 276-279.

Li, J. R., Kuppler, R. J. \& Zhou, H. C. (2009). Chem. Soc. Rev. 38, 1477-1504.

Liang, W. \& D'Alessandro, D. M. (2013). Chem. Commun. 49, 37063708.

Lin, X., Telepeni, I., Blake, A. J., Dailly, A., Brown, C. M., Simmons, J. M., Zoppi, M., Walker, G. S., Thomas, K. M., Mays, T. J., Hubberstey, P., Champness, N. R. \& Schroder, M. (2009). J. Am. Chem. Soc. 131, 2159-2171.

Lu, Z. Z., Zhang, R., Li, Y. Z., Guo, Z. J. \& Zheng, H. G. (2011). J. Am. Chem. Soc. 133, 4172-4174.

Martinez Joaristi, A., Juan-Alcañiz, J., Serra-Crespo, P., Kapteijn, F. \& Gascon, J. (2012). Cryst. Growth Des. 12, 3489-3498.

Maspoch, D., Ruiz-Molina, D., Wurst, K., Domingo, N., Cavallini, M., Biscarini, F., Tejada, J., Rovira, C. \& Veciana, J. (2003). Nat. Mater. 2, 190-195.

McKinlay, A. C., Xiao, B., Wragg, D. S., Wheatley, P. S., Megson, I. L. \& Morris, R. E. (2008). J. Am. Chem. Soc. 130, 10440-10444.

Mohanty, P., Khine Linn, N. M. \& Landskron, K. (2009). Langmuir, 26, 1147-1151.

Noro, S., Kitagawa, S., Kondo, M. \& Seki, K. (2000). Angew. Chem. Int. Ed. 39, 2082-2084.

Ohi, H., Tachi, Y. \& Itoh, S. (2004). Inorg. Chem. 43, 4561-4563.

Okawa, H., Shigematsu, A., Sadakiyo, M., Miyagawa, T., Yoneda, K., Ohba, M. \& Kitagawa, H. (2009). J. Am. Chem. Soc. 131, 1351613522.

O'Keeffe, M., Peskov, M. A., Ramsden, S. J. \& Yaghi, O. M. (2008). Acc. Chem. Res. 41, 1782-1789.

O'Keeffe, M. \& Yaghi, O. M. (2012). Chem. Rev. 112, 675-702.

Pachfule, P., Chen, Y., Jiang, J. \& Banerjee, R. (2011). J. Mater. Chem. 21, 17737.

Panda, T., Pachfule, P., Chen, Y., Jiang, J. \& Banerjee, R. (2011). Chem. Commun. 47, 2011-2013.

Park, K. S., Ni, Z., Côté, A. P., Choi, J. Y., Huang, R., Uribe-Romo, F. J., Chae, H. K., O'Keeffe, M. \& Yaghi, O. M. (2006). Proc. Nat. Acad. Sci. 103, 10186-10191.

Perry, J. J., Kravtsov, V. Ch, McManus, G. J. \& Zaworotko, M. J. (2007). J. Am. Chem. Soc. 129, 10076-10077.

Rao, C. N. R., Natarajan, S. \& Vaidhyanathan, R. (2004). Angew. Chem. Int. Ed. 43, 1466-1496.

Reddy, M. L. \& Sivakumar, S. (2013). Dalton Trans. 42, $2663-$ 2678.

Ricco, R., Malfatti, L., Takahashi, M., Hill, A. J. \& Falcaro, P. (2013). J. Mater. Chem. A, 1, 13033-13045. 
Rocha, J., Carlos, L. D., Paz, F. A. \& Ananias, D. (2011). Chem. Soc. Rev. 40, 926-940.

Roques, N., Maspoch, D., Imaz, I., Datcu, A., Sutter, J.-P., Rovira, C. \& Veciana, J. (2008). Chem. Commun. pp. 3160-3162.

Roques, N., Maspoch, D., Luis, F., Camon, A., Wurst, K., Datcu, A., Rovira, C., Ruiz-Molina, D. \& Veciana, J. (2008). J. Mater. Chem. 18, 98-108.

Rosi, N. L., Eddaoudi, M., Kim, J., O'Keeffe, M. \& Yaghi, O. M. (2002). CrystEngComm, 4, 401-404.

Rowsell, J. L. \& Yaghi, O. M. (2004). Micropor. Mesopor Mater. 73, 3 14.

Sakakura, T., Choi, J.-C. \& Yasuda, H. (2007). Chem. Rev. 107, 23652387.

Shimomura, S., Higuchi, M., Matsuda, R., Yoneda, K., Hijikata, Y., Kubota, Y., Mita, Y., Kim, J., Takata, M. \& Kitagawa, S. (2010). Nat. Chem. 2, 633-637.

Shultz, A. M., Farha, O. K., Hupp, J. T. \& Nguyen, S. T. (2009). J. Am. Chem. Soc. 131, 4204-4205.

Son, W.-J., Kim, J., Kim, J. \& Ahn, W.-S. (2008). Chem. Commun. pp. 6336-6338.

Stavila, V., Bhakta, R. K., Alam, T. M., Majzoub, E. H. \& Allendorf, M. D. (2012). ACS Nano 6, 9807-9817.

Sumida, K., Rogow, D. L., Mason, J. A., McDonald, T. M., Bloch, E. D., Herm, Z. R., Bae, T.-H. \& Long, J. R. (2012). Chem. Rev. 112, 724-781.
Sun, C. Y., Wang, X. L., Qin, C., Jin, J. L., Su, Z. M., Huang, P. \& Shao, K. Z. (2013). Chem. Eur. J. 19, 3639-3645.

Vaidhyanathan, R., Iremonger, S. S., Shimizu, G. K., Boyd, P. G., Alavi, S. \& Woo, T. K. (2010). Science, 330, 650-653.

Wang, X., Ma, S., Forster, P., Yuan, D., Eckert, J., López, J., Murphy, B., Parise, J. \& Zhou, H. (2008a). Angew. Chem. Int. Ed. 47, 72637266.

Wang, X.-S., Ma, S., Forster, P. M., Yuan, D., Eckert, J., López, J. J., Murphy, B. J., Parise, J. B. \& Zhou, H.-C. (2008b). Angew. Chem. 120, 7373-7376.

Wang, C. \& Ying, J. Y. (1999). Chem. Mater. 11, 31133120.

Wong-Foy, A. G., Matzger, A. J. \& Yaghi, O. M. (2006). J. Am. Chem. Soc. 128, 3494-3495.

Wu, H., Zhou, W. \& Yildirim, T. (2009). J. Am. Chem. Soc. 131, 49955000.

Yoo, Y., Varela-Guerrero, V. \& Jeong, H. (2011). Langmuir, 27, 2652 2657.

Zacher, D., Shekhah, O., Wöll, C. \& Fischer, R. A. (2009). Chem. Soc. Rev. 38, 1418-1429.

Zhan, S.-Z., Li, M., Ng, S. W. \& Li, D. (2013). Chem. Eur. J., 19, 10217-10225.

Zornoza, B., Martinez-Joaristi, A., Serra-Crespo, P., Tellez, C., Coronas, J., Gascon, J. \& Kapteijn, F. (2011). Chem. Commun. 47, 9522. 